\title{
Prática pedagógica de Educação Ambiental no ensino de Geografia: necessidade de transição de paradigmas ${ }^{1}$
}

\author{
Sílvia de Freitas Alves² \\ Sandra de Fátima Oliveira ${ }^{3}$
}

Resumo: A Educação Ambiental (EA) é pensada como Educação, em suas várias dimensões, tanto no espaço educacional não formal - a comunidade, quanto no formal - a escola. Desse modo, os elementos teóricos e metodológicos que fundamentam as atividades de EA no ensino de Geografia merecem reflexão e análise. Este artigo visa contribuir para o desenvolvimento de práticas expressivas em EA, acompanhadas de reflexões críticas que possam acionar o valor educativo da Geografia, bem como demonstrar a necessidade de implantar políticas de formação de professores/as. As reflexões são desenvolvidas com base nos referenciais do método histórico-dialético, apresentado como uma possibilidade teórica de interpretação das realidades educacional e ambiental.

Palavras-chave: Educação Ambiental, Geografia, Escola.

Abstract: Environmental Education (EE) is conceived as Education, in its various dimensions, both in the non-formal educational space - the community - and in the formal one - the school. Thus, the theoretical and methodological elements that establish the activities of EE in the teaching of geography deserve reflection and analysis. This article aims to contribute to the development of expressive practices in EE with critical reflections that could trigger the educational value of Geography, as well as demonstrate the need to implement teacher education policies. The reflections are developed based on references from the historical and dialectical method, presented as a possible theoretical interpretation of the educational and environmental realities.

Keywords: Environmental Education, Geography, School.

${ }^{1}$ Este artigo faz parte de uma pesquisa de mestrado intitulada "Concepções de Educação Ambiental de Professoras de Geografia da Rede Municipal de Ensino de Goiânia: tendências reveladas", apresentada no dia 12 de junho de 2008 junto ao Programa de Pesquisa e Pós-graduação em Geografia da Universidade Federal de Goiás.

2 Professora de Geografia das redes estadual e municipal de ensino (Mestre em Geografia pelo Instituto de Estudos Socioambientais - UFG). Contato: Rua Narayola Q. 34, lote 21, edifício residencial Solar Park, apart. 207, bloco A-2 - Jardim Luz, Aparecida de Goiânia - GO.E-mail: geosilvia_58@hotmail.com.

3 Professora do Curso de Graduação e Pós-graduação em Geografia da Universidade Federal de Goiás. 
A partir do século XVIII, com a implantação da sociedade industrial, iniciaram-se processos de transformação no contexto econômico, político e social do Ocidente. Todavia, as conseqüências dessas transformações, que visavam o desenvolvimento tecnológico e industrial, foram desastrosas para a natureza, compreendida em suas diversas relações e interações com o meio natural, social, cultural, econômico e político.

Considerando-se o contexto de agravamento da crise ambiental instaurado no século XVIII e continuado nos séculos XIX e XX, optou-se por situar neste artigo os desafios da Geografia enquanto ciência que estuda a sociedade com base no espaço por ela produzido, bem como no ensino de Geografia que urge por transformações teórico-metodológicas no que diz respeito às práticas da EA formal. Sugere-se que esse esforço seja conjunto, tanto por parte dos pesquisadores, autores que pensam a Geografia no âmbito acadêmico-científico, quanto dos/as professores/as ${ }^{4}$ que fazem dessa área do conhecimento o seu cotidiano através da sua atividade docente.

Segundo Pereira e Carvalho (1991), o objetivo do ensino de Geografia no ensino fundamental poderia ser o de familiarizar os/as educandos/as com os conceitos básicos e necessários para uma apreensão geográfica do espaço no qual eles vivem. Conforme esses autores, tal procedimento irá compor um substrato teórico que permitirá aos/às educandos/as compreender o objetivo com o qual a Geografia trabalha. Espera-se, portanto, que os/as educandos/as tenham condições de utilizar categorias como: paisagem, espaço, lugar, natureza, meio ambiente e sociedade, entre outras, já que são ferramentas básicas para a compreensão do mundo em que vivem.

Para Filho e Almeida (1991), cabe também à Geografia, juntamente com outras áreas do conhecimento, desenvolver nos educandos/as a capacidade de observar, analisar, interpretar e pensar com criticidade a realidade, tendo em vista sua transformação. Nesse sentido, a temática ambiental insere-se como um dos desafios pedagógicos no ensino

\footnotetext{
${ }^{4}$ Neste texto, aceitando a recomendação da Rede de Gênero, buscou-se evitar uma linguagem sexista.
} 
dessa disciplina. Entretanto, tal temática não deverá ser conduzida apenas pelo viés pedagógico, devendo ser consideradas as características políticas, sociais e ideológicas nela contidas. Nesse processo de ampliação da abordagem da questão ambiental no ensino de Geografia, cabe aos/as professores/as o encaminhamento para discussões, em sala de aula, dos vários aspectos que envolvem a questão ambiental.

Acredita-se que o principal objetivo de se trabalhar o tema Meio Ambiente no ensino de Geografia, especialmente no ensino fundamental, seja contribuir para a formação de cidadãos conscientes que possam atuar na realidade socioambiental de forma comprometida com a vida em suas várias dimensões. Para tanto, torna-se importante que a escola proponha atividades para além de informações e conceitos, trabalhando a formação de valores e mudanças de atitudes em relação à vida. Todavia, tanto a sociedade quanto a família também são responsáveis por essa tarefa, que não pode ser delegada apenas à escola e aos/às educadores/as.

Com base nesse entendimento, observam-se nos Parâmetros Curriculares Nacionais: Meio Ambiente (1996, p. 4) as diretrizes para um trabalho educativo com a temática ambiental direcionadas para as interações dos aspectos naturais, sociais e culturais:

Esse tema trata em especial da busca de caminhos pessoais e coletivos que levem ao estabelecimento de relações econômicas, sociais e culturais cada vez mais adequadas à promoção de uma boa qualidade de vida para todos, tanto no presente quanto no futuro.

Sabe-se que a temática ambiental é apresentada pela mídia, principalmente pela televisão, através de informações superficiais e muitas vezes equivocadas. Entretanto, essa mesma mídia constitui, na maioria dos casos, a única fonte de informações que educa as famílias e a maioria das crianças e adolescentes. Desse modo, compete aos/às educadores/as fazer com que as informações e os valores veiculados pela mídia e trazidos de casa para a sala de aula provoquem discussões salutares no processo de aprendizagem. Cabe aos/às educadores/as trabalhar com seus educandos/as a fim de desenvolver uma postura crítica acerca da realidade vivida por ambas as partes. 
Tendo em vista que o meio ambiente e suas implicações para a vida dos seres humanos neste planeta são objetos de estudo da EA, cabe aos profissionais do ensino de Geografia instrumentalizar e conduzir educandos/as à construção do conhecimento complexo, superando ou pelo menos tentando superar a compartimentação herdada do paradigma da ciência moderna. Tal compreensão pressupõe que a EA seja enfocada, tanto no ensino de Geografia quanto no das demais áreas do conhecimento, seguindo-se o que defende Reigota (1995, p. 10):

A educação ambiental é uma proposta que altera profundamente a educação como a conhecemos, não sendo necessariamente uma prática pedagógica voltada para a transmissão de conhecimentos sobre ecologia. Trata-se de uma educação que visa não só à utilização racional dos recursos naturais [...] mas basicamente à participação dos cidadãos nas discussões e decisões sobre a questão ambiental.

O ensino de Geografia na perspectiva em estudo constitui um desses saberes que podem ser utilizados como instrumento de ação e reflexão para a garantia de um ambiente saudável. Assim, por meio de um trabalho interdisciplinar, poder-se-á implementar ações pedagógicas de transformação da realidade e também de desenvolvimento de um saber geográfico com uma nova visão de mundo. Acredita-se que, desse modo, os/as educandos/as possam compreender melhor o espaço em que vivem, seja no âmbito local ou global. Isso certamente implicará a construção de um novo paradigma que contribua com o desafio dos/as educadores/as de transpor a lógica cartesiana imposta pela ciência moderna. Sabe-se que essa lógica fragmenta os saberes e compromete a atuação dos referidos profissionais em circunstâncias como a identificação das conseqüências do impacto produzido nas questões ambientais globais de nossa realidade e sua influência, ativa e política, no processo de construção dessa mesma realidade.

Os desafios impostos de forma geral e específica aos/às professores/as de Geografia são grandes. Há que se trabalhar com valores e comportamentos, tais como: solidariedade, cooperação, respeito mútuo, além de estimular uma visão global e crítica das questões ambientais, assim como procurar estabelecer um enfoque interdisciplinar que, acima de tudo, 
construa saberes significativos à vida dos educandos/as. Conduzir a prática da EA permeada pelo paradigma cartesiano é praticamente impossível porque essa visão de mundo é incompatível com o avanço de uma sociedade na qual prevaleçam os valores individuais e coletivos.

Processos educativos comprometidos com a sustentabilidade e a participação podem formar cidadãos e cidadãs capazes de compreender e conduzir bem essa transição de paradigmas. Essa é uma das tarefas da EA, e entende-se que ela não contém uma especificidade isolada e desconectada da realidade, mas, pelo contrário, existe enquanto uma dimensão da educação e luta por transformações de toda a educação. Assim, reafirmar a função da escola não é apenas transmitir conteúdos, mas propiciar a construção da subjetividade para que as crianças e adolescentes tenham condições de pensar e agir.

O ensino de Geografia nas séries iniciais apresenta características muito peculiares no seu fazer. Entretanto, essas características do fazer pedagógico, ou seja, do ensinar Geografia para crianças e adolescentes, muitas vezes revelam uma visão distorcida ou superficial por não considerar tanto os pressupostos teóricos e metodológicos quanto os pressupostos epistemológicos da Ciência Geográfica.

Nesse aspecto, há que se evidenciar o papel do/a professor/a de Geografia como mediador da construção dos conhecimentos, da interpretação e relação das informações com a experiência vivida pelos/as educandos/as. Para tanto, é preciso saber ouvir as crianças/adolescentes e estimular sua participação. Mais ainda: utilizar essas participações como estratégia de abordagem e direcionamento das discussões em sala de aula.

A EA, enquanto uma prática pedagógica, não se realiza sozinha, mas nas relações dos seres humanos com o ambiente e dos/as educandos/as com o ambiente escolar e também na interação dos/as educandos/as mediados/as pelos/as educadores/as. Nesse sentido, Leme (2006, p. 109) destaca que a compreensão parcial da problemática ambiental, atrelada a uma visão acrítica do papel da educação na sociedade, implica a promoção de um tipo de EA hegemônica (de senso comum) em vez de uma EA crítica.

Pensa-se, entretanto, o papel da EA como um instrumento que sirva para estimular a reflexão e propiciar conhecimento. E mais: que esse 
conhecimento sirva para subsidiar a participação. Todavia, a participação é um processo que exige o sentimento de pertencimento. Como se depreende das palavras de Brandão (1995-1996), a EA é uma das vocações da educação que se inspiram tanto nos valores de respeito a todas as formas de vida e de solidariedade quanto na necessidade de se adquirir conhecimento específico a respeito da problemática ambiental.

Essa perspectiva de orientar as práticas pedagógicas desenvolvendo atitudes e valores voltados para a vida é o caminho mais profícuo para instrumentalizar o processo educativo ambiental crítico. A participação é, assim, outro eixo integrador nesse processo educativo ambiental que remete tanto à reflexão quanto à ação. Para Segura (2001, p. 44), ao "assumir esse referencial, a EA participativa tem como suposto básico criar as condições para o diálogo e a percepção de direitos e deveres e a intervenção consciente na realidade".

Concorda-se que a participação é condição necessária nas práticas de EA e, considerando-se o péssimo quadro da crise ambiental em que se encontra nosso planeta, esta representa um instrumento essencial para a mudança das relações entre os seres humanos (sociedade) e o ambiente. Segundo Jacobi (2003), a relação entre meio ambiente e educação para a cidadania assume um papel cada vez mais desafiador e demanda a emergência de novos saberes para apreender processos sociais que se complexificam e riscos ambientais que se intensificam.

\section{Práxis de Educação Ambiental na escola e sua relação com a vida}

A questão ambiental entendida como a relação sociedade/natureza faz parte da práxis educativa, assim como do cotidiano das pessoas. Desse modo, a análise das relações do cotidiano dentro das escolas pode contribuir para a compreensão de como as práticas educativas ambientais são carregadas de conflitos, emoções, possibilidades, desejos, ingenuidades e também de confusões teóricas e metodológicas.

Tal como entende Loureiro (2004), espera-se que a práxis educativa seja cultural e informativa, política, formativa e emancipadora e que, por isso, seja transformadora das relações sociais. Acredita-se que o papel do/a professor/a de Geografia enquanto educador/a ambiental seja 
propor mudanças de posturas que conduzam a mudanças de valores e, conseqüentemente, melhor qualidade de viver. Para Leff (2005, p. 85), essas mudanças geram nova ética, o que ele chama de racionalidade ambiental:

Desse modo, a racionalidade ambiental se funda numa nova ética que se manifesta em comportamentos humanos em harmonia com a natureza; em princípios de uma vida democrática e em valores culturais que dão sentido à existência humana. Estes se traduzem num conjunto de práticas sociais que transformam as estruturas do poder associadas à ordem econômica estabelecida, mobilizando um potencial ambiental para a construção de uma racionalidade social alternativa.

Ante o exposto, depreende-se que não há como separar a chamada racionalidade ambiental defendida por Leff dos contextos econômicos, sociais, políticos e culturais que permeiam a vida dos seres humanos. Assim sendo, a mudança de paradigmas se faz urgente, pois o modo de produção vigente tem, entre outros fundamentos, o consumismo exacerbado e a conseqüente destruição da natureza em função do lucro fácil. Leff (2005, p. 85) ressalta que o sistema de valores que se vivencia atualmente é resultado da formação social vigente: "Toda formação social e todo tipo de desenvolvimento estão fundados num sistema de valores, em princípios que orientam as formas de apropriação social e transformação da natureza". Cabe então uma mudança de valores em que a relação seres humanos/natureza seja de fato mediada por outros valores com base no desenvolvimento social e na valorização da vida.

Sobre esse assunto, Guattari (2000, p. 7) chama a atenção para o fato de que a vida humana nesse contexto socioeconômico se encontra ameaçada. Ele assim se expressa:

O planeta Terra vive um período de intensas transformações técnico-científicas, em contrapartida das quais engendram fenômenos e desequilíbrios ecológicos que, se não forem remediados, no limite, ameaçam a implantação da vida em superfície. 
Concorda-se com Carvalho (2006) no tocante à necessidade de se entender que o grande desafio da EA formal é ir para além de mudanças comportamentais. Para a autora, faz-se premente mais que mudanças de comportamento isoladas e individuais. É imprescindível discutir os conceitos e as abordagens associadas à prática da EA como uma prática mais coerente com a questão ambiental, o que certamente possibilita estabelecer uma relação mais harmônica com as diversas formas de vida.

Ao se pensar a EA para a vida, há que se considerar suas diversas implicações para o contexto escolar e, sobretudo, (re)definir práticas, currículos, conteúdos, conceitos, métodos de ensino. Com muita propriedade, Gadotti (2000, p. 42) salienta a importância de os conteúdos programáticos terem relação com a vida:

Os conteúdos das disciplinas do saber escolar atual refletem ainda o currículo clássico. A vida cotidiana, a violência, a sensibilidade, a subjetividade não são levadas em conta. Há muito de arbitrário e cultural na escolha de conteúdos programáticos. Nos últimos anos, as novas propostas curriculares começam a dar cada vez mais importância aos chamados 'temas transversais' - ética, saúde, meio ambiente, diversidade cultural, gênero, consumo etc. -, realçando os vínculos entre educação e vida. A educação deve ser tão ampla quanto a vida.

Sabe-se que as práticas pedagógicas realizadas na escola podem contribuir com visões de mundo dos/as educandos/as e, conseqüentemente, com suas maneiras de viver bem se relacionando, sentindo e pensando. Dessa forma, cabe aos educadores/as a tarefa de fundamentar as ações educativas em valores que respaldem a continuidade da vida no planeta. Então, há que se buscar um embasamento teórico que esteja preocupado com o senso crítico, com as questões sociais, como desemprego, fome, violência, saúde, discriminação (de raça, de gênero, religiosa e outras) e com a degradação ambiental. Sendo assim uma educação geográfica respaldada na observação, no conhecimento através da leitura do mundo e no conhecimento do meio em que se vive, deve ter como objetivo incluir a vida em suas diversas dimensões políticas, econômicas, culturais, espirituais, éticas e sociais. 
Considera-se que, no ensino de Geografia, os conceitos de espaço, lugar e cotidiano sejam fundamentais para o entendimento da prática pedagógica da EA. Buscou-se, então, neste artigo, fazer algumas reflexões sobre essas categorias.

\section{Conceitos de espaço, lugar e cotidiano: relação dialética na prática pedagógica da Educação Ambiental no ensino de Geografia}

A crise ambiental instaurada pelo modelo socioeconômico vigente, cuja trajetória reforçou a dicotomia sociedade/natureza, pressupõe a necessidade de conscientização, mudanças de valores, de atitudes e de paradigmas no âmbito educacional e, sobretudo, a compreensão de como se estabelecem as práticas da EA na dimensão escolar. Nesse contexto, emergem as seguintes questões: como poderia a EA formal efetivar uma reflexão da problemática ambiental? Como os/as educadores/as, especialmente os/as professores/as de Geografia, medeiam suas concepções de meio ambiente e EA tendo por base seus referenciais teóricos e metodológicos?

Para Penin (1994), o processo de construção do conhecimento dos professores/as é fundamentado em suas representações, constituídas por concepções e vivências. Acredita-se que as concepções de meio ambiente e de EA, por sua vez, são mediadas pelos referenciais teóricos e metodológicos utilizados na prática da EA no ensino de Geografia. Dada a importância de se compreender a prática educativa, faz-se necessário contextualizar e despertar a reflexão de como as categorias espaço, lugar e cotidiano se apresentam na prática da EA no ensino dessa disciplina.

Os conceitos de lugar e cotidiano são elementos basilares para a compreensão de práticas de EA realizadas nas escolas, uma vez que a escola é um espaço de transformação social, compreendendo espaço como o resultado da experiência humana histórica e cultural, que tem como fundamento as relações sociais. Para Heller (2000, p.20), "a vida cotidiana não está fora da história, mas no centro do acontecer histórico: é a verdadeira essência da substância social".

Carlos (2007, p. 22), ao apresentar sua leitura sobre lugar, assim se expressa: 
Lugar é produto das relações humanas, entre homem e natureza, tecido por relações sociais que se realizam no plano do vivido o que garante a construção de uma rede de significados e sentidos que são tecidos pela história e cultura civilizadora produzindo a identidade, posto que é aí que o homem se reconhece porque é o lugar da vida.

Já para Santos (2004, p. 332), o conceito de lugar, entendido como produto da experiência humana, é definido da seguinte forma: "no lugar um cotidiano compartido entre as mais diversas pessoas, firmas e instituições - cooperação e conflito são a base da vida em comum". Assim, o conceito de lugar é extremamente relevante na perspectiva da EA, uma vez que, conhecendo-se o cotidiano dos indivíduos, poder-se-á chegar próximo a uma transformação do ponto de vista efetivo do ser. Por conseguinte, o conhecimento da cotidianidade do indivíduo é o ponto de partida para a sua sensibilização. Certamente, isso torna mais visíveis os elementos de degradação ambiental, até então distantes de sua vivência. Nesse aspecto, Penin (1994, p. 38) ressalta: "Para que haja verdadeiramente a construção do conhecimento há que se coordenar vivido e concebido".

Entende-se que as relações cotidianas são mediadas entre o imediato vivido e as grandes questões globais. Loureiro (2004, p. 133) salienta que "não existe cidadania planetária sem que o indivíduo crie o senso de pertencimento e seja cidadão de algum lugar e de um Estadonação, exercitando e redefinindo o próprio sentido de cidadania". Desse modo, no processo pedagógico voltado para a prática da EA não há desprezo do local, do cotidiano, da ação teoria-prática. Muito pelo contrário, esses pressupostos possibilitam o diálogo e as ações educativas.

Nesse sentido, concorda-se com Bispo e Oliveira (2007, p. 73) que o lugar é o palco onde se manifesta a ação:

É onde as relações são tecidas e partilhadas. É a realidade sensível de caráter emocional e afetivo em constante transformação, com ligações espaciais próprias que o caracterizam com uma carga também social, econômica, com processos lúdicos, de crenças e de imaginários. 
Freire (2001, p. 33) também ressalta a importância de o/a professor/a trabalhar o lugar como resultado das relações que se estabelecem entre as pessoas em seus cotidianos:

Por que não aproveitar a experiência que têm os alunos de viver em áreas da cidade descuidadas pelo poder público para discutir, por exemplo, a poluição dos riachos e dos córregos e os baixos níveis de bem-estar das populações, os lixões e os riscos que oferecem à saúde das gentes?

Ademais, não há como negligenciar o espaço vivenciado pelos/as educandos/as se o objetivo é torná-los capazes de situar a si próprios, capacitá-los para a leitura do mundo, transformando-o e, sobretudo, atribuindo significado a seus modos de viver. Entende-se, portanto, que o/a educador/a ambiental, ao discutir e criticar as relações cotidianas, deve considerar em sua forma de viver e interpretar o mundo os pressupostos que sugerem uma EA que promova um novo paradigma de sociedade.

Do ponto de vista pedagógico, as noções de espaço e de lugar não podem ser consolidadas de forma linear, através de procedimentos didáticos que partam de noções simples e concretas para as mais abstratas. Concorda-se, então, com o entendimento de Loureiro et al. $(2000,2003)$ de que no processo pedagógico de abordagem da EA é necessário partir da realidade de vida, do local e do cotidiano dos educandos/as para construir uma compreensão mais integrada de meio ambiente em diferentes escalas - local, regional, nacional e global. Também para Gadotti (2003, p. 24), a vida dos indivíduos acontece em um determinado lugar, e as transformações históricas só se realizam quando incorporadas aos seus modos de vida e às suas existências cotidianas. "É no cotidiano que podemos aprender a nos olhar, aprender a falar, a ouvir, a ver, a viver uma vida banal ou não [...]".

Tomando-se por base esses pressupostos, estabelecer ligações entre a cidade, o bairro, a rua, a escola e outros lugares possibilita estabelecer relações entre as experiências cotidianas dos educandos/as com seus espaços de vivência. Isso permite também dar significado às formas de viver e de se apropriar do espaço. Entretanto, Straforini (2002, p. 99) chama a atenção para que, no ensino de Geografia nas séries iniciais, se 
evitem fragmentações pautadas em concepções lineares de mundo que possam facultar aos/às educandos/as uma compreensão reduzida do espaço. Ressalta ainda que estabelecer relações entre diferentes escalas e tempos é o mais recomendado. Para esse autor, no ensino de Geografia nas séries iniciais, o ponto de partida deve ser o lugar, porém, este deve ser relacionado com outras lógicas tanto locais quanto globais.

Sabe-se que a Geografia é um dos instrumentos importantes para a compreensão do mundo, portanto, pensar o mundo implica tomar as noções de espaço, lugar e cotidiano como conteúdos que facultem a aprendizagem para a vida em suas diversas dimensões. Cavalcanti (2002, p. 78) afirma que "instrumentalizar o cidadão para a compreensão do espaço tal como hoje ele está produzido é o papel da escola e da Geografia no ensino". Entretanto, para que isso seja de fato concretizado, a autora ressalta que os/as professores/as devem considerar os saberes que os/as educandos/as trazem do seu cotidiano, de modo que sejam confrontados com o saber geográfico. Nessa perspectiva, o cotidiano constitui o eixo articulador que, vinculado à aprendizagem do espaço, estabelecerá significados às formas de viver, habitar, relacionar-se consigo mesmo, com os outros e também com a natureza, ou seja, produzir significados para o vivido.

Entende-se que a EA no ensino de Geografia, tendo como ponto de partida o lugar, leva em consideração o espaço vivido no/do cotidiano, o que possibilita uma melhor compreensão das relações sociais, políticas, culturais e éticas, bem como do mundo globalizado. Destarte, é em escala local que se estabelece o cotidiano, mas na cotidianidade o global não deixa de existir, conforme afirma Santos:

A ordem global funda as escalas superiores ou externas à escala do cotidiano. [...] A ordem local funda a escala do cotidiano, e seus parâmetros são a co-presença, a vizinhança, a intimidade, a emoção, a cooperação e a socialização com base na contigüidade (SANTOS, 2004, p. 339).

Outra leitura sobre a relação lugar-cotidiano pautada na relação local/global se encontra em Carlos (2007, p. 20): 
O caminho que se abre à análise é pensar o cotidiano - onde se realizam o local e o mundial - que é tecido pelas maneiras de ser, conjunto de afetos, as modalidades do vivido, próprios a cada habitante produzindo uma multiplicidade de sentidos. Podemos buscar o entendimento do lugar nas práticas mais banais e familiares o que incita pensar a vida cotidiana segundo a lógica que lhe é própria e que se instala no insignificante, no parcelar, no plural.

Do ponto de vista da Geografia escolar voltada para a EA, é extremamente importante a perspectiva do estudo do espaço através da percepção do lugar e das relações existentes nas paisagens locais/globais. Entretanto, em termos pedagógicos, não há como estabelecer relações entre sociedade e natureza sem um processo contínuo de diálogo que resulte em mudanças nos métodos de ensino, nos currículos, nos conteúdos e principalmente nas práticas docentes. Entende-se que, para transformar as práticas pedagógicas compreendidas como resultados de processos históricos e culturais, que permeiam a vida, é necessária uma aprendizagem integrada.

Nesse aspecto, Morais e La Torre (2004, p. 82) compreendem que a aprendizagem integrada na atual estrutura curricular, fragmentada, não é uma tarefa fácil. É preciso, pois, envidar esforços conjuntos para a realização de práticas pedagógicas que estimulem os diferentes sentidos, a imaginação, a intuição, a cooperação e, sobretudo, despertem a subjetividade:

A aprendizagem integrada poderia ser descrita como o processo mediante o qual vamos construindo novos significados das coisas e do mundo ao nosso redor, ao mesmo tempo em que melhoramos estruturas e habilidades cognitivas, desenvolvemos novas competências, modificamos nossas atitudes e valores, projetando tais mudanças na vida, nas relações sociais e laborais.

Dessa forma, as práticas educativas ambientais contribuem com reflexões acerca da crise ambiental em que se vive. Para tanto, os/as educadores/as podem utilizar situações do cotidiano, cujo eixo norteador seria a realidade vivida pelos educandos/as em seus bairros, ruas ou até mesmo dentro da escola, e vários recursos, como: filmes, músicas, 
excursões, espetáculos artísticos, dramatizações e muitas outras situações ocasionais da vida.

\section{Considerações finais}

São perceptíveis os sinais de movimentos de transição de referenciais teórico-metodológicos e de interpretação da realidade, e são esses sinais que revelam o caráter dinâmico da construção de idéias e valores que dão forma à prática educativa ambiental nas escolas.

Acredita-se, dessa forma, que este artigo possa contribuir com reflexões sobre a prática da Educação Ambiental em nível formal, tendo em vista as seguintes questões: como lidar com a fragilidade da Educação ambiental nas escolas enquanto prática pedagógica? Quais seriam as tendências, os procedimentos e os caminhos mais adequados para desenvolvê-la?

Nesse sentido, buscou-se discutir a necessidade de promoção de ações educativas mais adequadas, bem como de capacitação dos/as professores/as de Geografia e, conseqüentemente, de melhoria na qualidade de ensino nas escolas.

Considera-se essa abordagem significativa como instrumento que poderá nortear práticas pedagógicas conscientes, críticas e transformadoras no ambiente escolar. Tendo em vista que os paradigmas de interpretação da realidade interferem no trabalho pedagógico e afetam diretamente o que se pretende ensinar, fez-se pertinente destacar alguns elementos da prática educativa em EA no ensino de Geografia. Ante o exposto, torna-se imprescindível a implementação de um sistema conceitual teórico ou, pelo menos, de um discurso conceitual organizado, com vista a enfrentar e interpretar os fluxos de mudanças ou mesmo acionar o valor educativo da Geografia para que os/as estudantes possam situar-se no mundo e, acima de tudo, compreendê-lo. 


\section{Referências}

BISPO, Marciléia Oliveira; OLIVEIRA, Sandra de Fátima. Lugar e cotidiano: categorias para compreensão de representações em meio ambiente e educação ambiental. Revista Brasileira de educação ambiental - Rede Brasileira de Educação Ambiental. Brasília, n. 2, p. 6976, fev. 2007.

BRANDÃO, Carlos Rodrigues. O que é educação. São Paulo: Brasiliense, 1995.

Educação Ambiental: uma vocação entre outras da educação. Educador Ambiental, São Paulo, ano 2, n. 11, nov. 1995 / jan. 1996.

BRASIL. Secretaria de Educação Fundamental. Ministério da Educação e Cultura. Parâmetros Curriculares Nacionais: Meio Ambiente e Saúde. Temas Transversais, v. 9, 3. ed. Brasília: MEC/SE, 1996.

CARLOS, Ana Fani. O lugar no/do mundo. São Paulo, 2007. Disponível em: <http:// www.fflch.usp.br/dg/gesp>. Acesso em: 18 dez. 2007.

CARVALHO, Isabel Cristina de Moura. Educação Ambiental: a formação do sujeito ecológico. 2. ed. São Paulo: Cortez, 2006.

CAVALCANTI, Lana de Souza. Geografia e práticas de ensino. Goiânia: Alternativa, 2002.

FILHO, Fadel David Antônio; ALMEIDA, Rosângela Doin. A questão metodológica no ensino de Geografia: uma experiência. Revista Terra Livre, São Paulo, n. 8, p. 91-100, 1991.

FREIRE, Paulo. Pedagogia da autonomia: saberes necessários à prática educativa. 18. ed. Rio de Janeiro: Paz e Terra, 2001.

GADOTTI, Moacir. Pedagogia da Terra. 4. ed. São Paulo: Peirópolis, 2000. (Série Brasil Cidadão).

. Saber aprender: um olhar sobre Paulo Freire e as perspectivas atuais da educação. In: LINHARES, Célia; TRINDADE, Maria Nazan (Org.). Compartilhando o Mundo com Paulo Freire. São Paulo: Cortez, 2003.

GUATTARI, Félix. As Três Ecologias. São Paulo: Papirus, 2000.

HELLER, Agnes. O cotidiano e a história. 6. ed. São Paulo: Paz e Terra, 2000.

JACOBI, Pedro. Educação ambiental, cidadania e sustentabilidade. Cadernos de pesquisa, São Paulo, v. 113, p. 189-205, mar. 2003.

LEME, Taciana Neto. Os conhecimentos práticos dos professores: (re)abrindo caminhos para a educação ambiental na escola. São Paulo: Annablume, 2006.

LOUREIRO, Carlos Frederico Bernardo. Trajetória e Fundamentos da Educação Ambiental. São Paulo: Cortez, 2004. Bahia, 2003.

(Org.). Cidadania e meio ambiente. Salvador. Centro de Recursos Ambientais da

LOUREIRO, Carlos Frederico Bernardo; LAYRARGUES, Philippe Pomier; CASTRO, Ronaldo Souza de (Org.). Sociedade e meio ambiente: a Educação Ambiental em debate. São Paulo: Cortez, 2000.

LEFF, Enrique. Epistemologia ambiental. São Paulo: Cortez, 2001. 
- Saber Ambiental: Sustentabilidade, Racionalidade, Complexidade, Poder. 4. ed. Petrópolis: Vozes, 2005.

MORAES, Maria Cândida; LA TORRE, Saturnino de. Sentipensar: fundamentos e estratégias para reencantar a educação. Petrópolis: Vozes, 2004.

PENIN, Sônia Terezinha de Souza. A aula: espaço de conhecimento, lugar de cultura. São Paulo: Papirus, 1994.

Cotidiano e escola: a obra em construção. 2. ed. São Paulo: Cortez, 1995.

PEREIRA, Diamantino; SANTOS, Douglas; CARVALHO, Marcos. Geografia no $1^{\circ}$ grau: algumas reflexões. Revista Terra Livre, São Paulo, n. 8, p. 121-131, 1991.

REIGOTA, Marcos. Meio Ambiente e representação social. São Paulo: Cortez, 1995.

SANTOS, Milton Almeida dos. Natureza do espaço: Técnica, Tempo, Razão e Emoção. São Paulo: Hucitec, 2004.

SEGURA, Denise de Souza Baena. Educação Ambiental na escola pública: da curiosidade ingênua à consciência crítica. São Paulo: Annablume: Fapesp, 2001.

STRAFORINI, Rafael. A totalidade mundo nas primeiras séries do ensino fundamental: um desafio a ser enfrentado. Revista Terra Livre, São Paulo, v. 1, n. 18, p. 95-114, jan. 2002.

Artigo: recebido em 19/06/2008 - aprovado em 08/12/2008 